\title{
Sensitivity of two SARS-CoV-2 variants with spike protein mutations to neutralising antibodies
}

\author{
Katharina Müller ${ }^{1,2} \cdot$ Philipp Girl $^{1,2}(1) \cdot$ Andreas Giebl $^{3} \cdot$ Stefanie Gruetzner ${ }^{3} \cdot$ Markus Antwerpen $^{1,2}$. \\ Elham Khatamzas ${ }^{4,5} \cdot$ Roman Wölfel $^{1,2} \cdot$ Heiner von Buttlar ${ }^{1,2}$
}

Received: 28 July 2021 / Accepted: 22 September 2021 / Published online: 4 October 2021

(c) The Author(s) 2021

\begin{abstract}
SARS-CoV-2 infections elicit a humoral immune response capable of neutralising the virus. However, multiple variants have emerged with mutations in the spike protein amongst others, the key target of neutralising antibodies. We evaluated the neutralising efficacy of 89 serum samples from patients, infected with SARS-CoV-2 in the beginning of 2020, against two virus variants isolated from acutely infected patients and harbouring spike protein mutations. One isolate was assigned to lineage B.1.351 (MUC-IMB-B.1.351) whilst the other (MUC-484) was isolated from an immunocompromised patient, sharing some but not all mutations with B.1.351 and representing a transitional variant. Both variants showed a significant reduction in neutralisation sensitivity compared to wild-type SARS-CoV-2 with MUC-IMB-B.1.351 being almost completely resistant to neutralisation. The observed reduction in neutralising activity of wild-type-specific antibodies against both variants suggests that individual mutations in the spike protein are sufficient to confer a potent escape from the humoral immune response. In addition, the effect of escape mutations seems to accumulate, so that more heavily mutated variants show a greater loss of sensitivity to neutralisation up to complete insensitivity as observed for MUC-IMB-B.1.351. From a clinical point of view, this might affect the efficacy of (monoclonal) antibody treatment of patients with prolonged infections as well as patients infected with variants other than the donor. At the same, this could also negatively influence the efficacy of current vaccines (as they are based on wild-type spike protein) emphasising the need to thoroughly surveil the emergence and distribution of variants and adapt vaccines and therapeutics accordingly.
\end{abstract}

Keywords COVID-19 $\cdot$ SARS-CoV-2 $\cdot$ Variants of concern $\cdot$ B.1.351 $\cdot$ Mutation E484K $\cdot$ Neutralising antibodies $\cdot$ Immune escape

Edited by William Dundon.

Katharina Müller and Philipp Girl have contributed equally to this work.

Philipp Girl

philippgirl@bundeswehr.org

1 Bundeswehr Institute of Microbiology, Munich, Germany

2 German Centre for Infection Research (DZIF), Partner site Munich, Munich, Germany

3 Medical Faculty, Institute for Transfusion Medicine and Haemostasis, University of Augsburg, Augsburg, Germany

4 Department of Medicine III, LMU Hospital Munich, Munich, Germany

5 Present Address: Heidelberg University Hospital, Heidelberg, Germany

\section{Introduction}

SARS-CoV-2 has steadily changed its genome through mutations during its global spread amongst humans. Such mutations can in principle affect the entire viral genome. Of particular interest, though, are those that occur in the spike (S) protein are of particular interest, since this protein is responsible for binding to the human ACE2 receptor and is thus indispensable for virus cell entry. It is therefore not surprising that the $\mathrm{S}$ protein and in particular its receptor binding domain has been identified as the key target for eliciting potent neutralising antibodies (NAbs), likely protecting against reinfection [1,2]. Moreover, the therapeutic administration of monoclonal antibodies (mAbs) and convalescent plasma from recovered patients is successfully applied worldwide. 
However, several novel variants that have recently emerged harbour a number of mutations, some of which are in the gene encoding the $S$ protein [3]. This has sparked questions about their humoral immune evasion potential and the protective capability of wild-type (WT)-specific NAbs against such virus variants. In this context, we analysed serum samples from convalescent plasma donors infected with SARS-CoV-2 at the onset of the pandemic (April-May 2020) and found a significant reduction in neutralising activity (47.7\%) when tested against Variant of Concern (VOC) B.1.1.7 (Alpha), confirming humoral immune evasion, at least to some extent [4]. To investigate this finding further, we reevaluated these samples and tested their neutralising effect on another VOC, B.1.351 (Beta), isolated from an acutely infected patient (MUCIMB-B.1.351). In addition, we also tested the neutralising capability of WT-specific NAbs against a SARS-CoV-2 strain (MUC-484), which originated in an immunocompromised patient during the course of a prolonged infection with multiple therapeutic plasma donations and was first described by Khatamzas et al. [5]. The previously described and early circulating strain MUC-IMB-1 (clade B1) served as WT reference virus [6].

Lineage B.1.351 (Beta), also known as 20H/501Y.V2, is one of multiple SARS-CoV-2 variants circulating globally and is classified as a VOC by the WHO [7]. It was first identified in South Africa and whilst it shares some mutations with B.1.1.7, it emerged independently [8]. It has a well described asparagine to tyrosine substitution (N501Y), which is also present in VOCs belonging to the B.1.1.7 and P.1 lineages [9]. In addition, it also hosts two other mutations E484K and K417N, both located in the ACE2 interaction surface of the S protein [10]. Interestingly, E484K was originally absent in B.1.1.7 including the strain we tested in our previous study. It was not until later that some B.1.1.7 isolates also acquired this particular mutation (commonly referred to as "B.1.1.7 enhanced") which was shown to reduce the sensitivity to WT Nabs of these enhanced isolates, allowing for an even greater humoral immune evasion [9]. Current studies suggest that this variant is more transmissible, likely due to carrying the early described D614G mutation associated with increased infectivity and has a significantly reduced susceptibility to various monoclonal antibody treatments as well as NAbs [11-14].

MUC-484 has several mutations, four of which are located within the S protein, including the D614G mutation. Most notably, the strain also acquired the E484K mutation present in B.1.351. However, it contains neither the abovementioned $\mathrm{N} 501 \mathrm{Y}$ nor the $\mathrm{K} 417 \mathrm{~N}$ mutation, making it an interesting variant to investigate the influence of $\mathrm{E} 484 \mathrm{~K}$ in absence of $\mathrm{N} 501 \mathrm{Y}$ and $\mathrm{K} 417 \mathrm{~N}$ compared with the more recent line B.1.351, which contains all three mutations.

\section{Materials and methods}

\section{Origin of serum samples}

As previously described [4], all samples were from patients which were hospitalised for their SARS-CoV-2 infection, but did not require mechanical ventilation. All samples were collected, according to the official guidelines of the German Federal Institute for Vaccines and Biomedicine [15] for the selection of plasma donors, 4 weeks after complete recovery. All had a serological profile consistent with recent SARS-CoV-2 infection (IgA/IgG antibodies, data not shown). Initially, 89 samples were tested against MUC-IMB-1 and MUC-B.1.351. However, nine samples were completely used up in the process, leaving only 80 samples to be tested against MUC-484.

\section{Isolation of SARS-CoV-2 variants}

Replication competent SARS-CoV-2 was isolated from a nasopharyngeal swab of a patient diagnosed with COVID19 by quantitative PCR with reverse transcription (RTqPCR). Whole genome sequencing of this isolate (from now on referred to as MUC-IMB-B.1.351) was performed in accordance with the German Regulation for molecular genetic surveillance of the coronavirus SARS-CoV-2. The second isolate (from now on referred to as MUC-484) derived from an immunocompromised patient and was previously described [5]. NGS sequencing and phylogenetic analyses of both SARS-CoV-2 isolates were performed as previously described [16]. Lollipop plots were subsequently generated using $\mathrm{R}$ in combination with the trackViewer libaray [17].

Both viruses were grown on Vero E6 cells. Viral stocks were prepared, titrated and stored at $-80{ }^{\circ} \mathrm{C}$ until further use.

\section{Micro-neutralisation test}

SARS-CoV-2 NAb titres were determined as previously described [18]. In brief, serum samples were serially diluted in duplicate in 96-well tissue culture plates starting at 1:5 to a maximum if $1: 640$ along with positive and negative control samples. Virus stocks $(50 \mathrm{TCID} / 50 \mu \mathrm{l})$ of B.1.351, MUC-484 and MUC-IMB-1 were prepared on Vero E6 cells; aliquots were stored at $-80{ }^{\circ} \mathrm{C}$ until further use. Each Virus was pre-incubated $\left(1 \mathrm{~h}, 37^{\circ} \mathrm{C}\right)$ with diluted samples before Vero E6 cells $\left(1 \times 10^{4}\right.$ cells $\left./ 50 \mu \mathrm{l}\right)$ were added to each well. After $72 \mathrm{~h}\left(37^{\circ} \mathrm{C}\right)$, supernatants were discarded and wells were fixed (13\% formalin/PBS) 
and stained with $0.1 \%$ crystal violet. The NAb titre corresponded to the reciprocal of the highest sample dilution showing complete inhibition of CPE. A virus re-titration was performed in triplicates on every plate and exact titres were determined by retrograde calculation.

\section{Results}

\section{Mutational changes in MUC-IMB-B.1.351}

We were able to generate a high-quality genome from a patient sample containing replication competent SARSCoV-2. The isolated genome holds 29,903 nucleotides in length, which equals $100 \%$ of the SARS-CoV-2 genome. The theoretically obtained sequencing depth was 1536 -fold. Sequencing analysis revealed 26 nonsynonymous mutations relative to the Wuhan sequence, assigning the isolate to the lineage B.1.351. An overview of all mutations is shown in Fig. 1A. Most notably, ten of the 26 mutations are located within the S protein. Prominent S-specific mutations include the amino acid changes K417N, E484K, N501Y and D614G. Moreover, amino acid changes D80A, D215G as well as the in-frame deletion $240 \Delta$ LLA are present in the $\mathrm{N}$-terminal domain (NTD) of the $\mathrm{S}$ protein.

As shown in Fig. 1B, MUC-484 contains only three nonsynonymous mutations in the S protein, including D614G, E484K and an in-frame deletion $(143 \Delta \mathrm{Y})$. In contrast to both variants, reference strain MUC-IMB-1 only has two nonsynonymous mutations present in its entire genome, one of which is located in the S protein (D614G) and also present in the other strains used in this study (Fig. 1C).

\section{Sensitivity of MUC-IMB-B.1.351 to sera from convalescent plasma donors}

Of the 89 samples tested, 73 were able to neutralise WT SARS-CoV-2 whilst for the remaining 16 samples no neutralising activity could be observed. Direct comparison of NAbs titres against MUC-IMB-1 and MUC-IMB-B.1.351 revealed that the vast majority of these positive serum samples (64/73) was unable to neutralise MUC-IMB-B.1.351. For the nine samples that partly retained their neutralising ability, a notable reduction was observed with a median decrease of $91.5 \%$ in neutralising activity. Altogether, the mean loss of neutralising activity against MUC-IMBB.1.351 was $99 \%$ and the observed decrease in titres was statistically significant $(p<0.0001$ by Wilcoxon). At the same time, all samples $(16 / 16)$ that initially tested negative for NAbs against WT virus were also unable to neutralise MUC-IMB-B.1.351 (Fig. 2).

Pearson regression analysis revealed only limited correlation ( $r=0.53$; 95\% CI: $0.37-0.67)$ between the NAb titre against WT SARS-CoV-2 and the titre against MUCIMB.1.351 of the same sample. (Fig. 3).

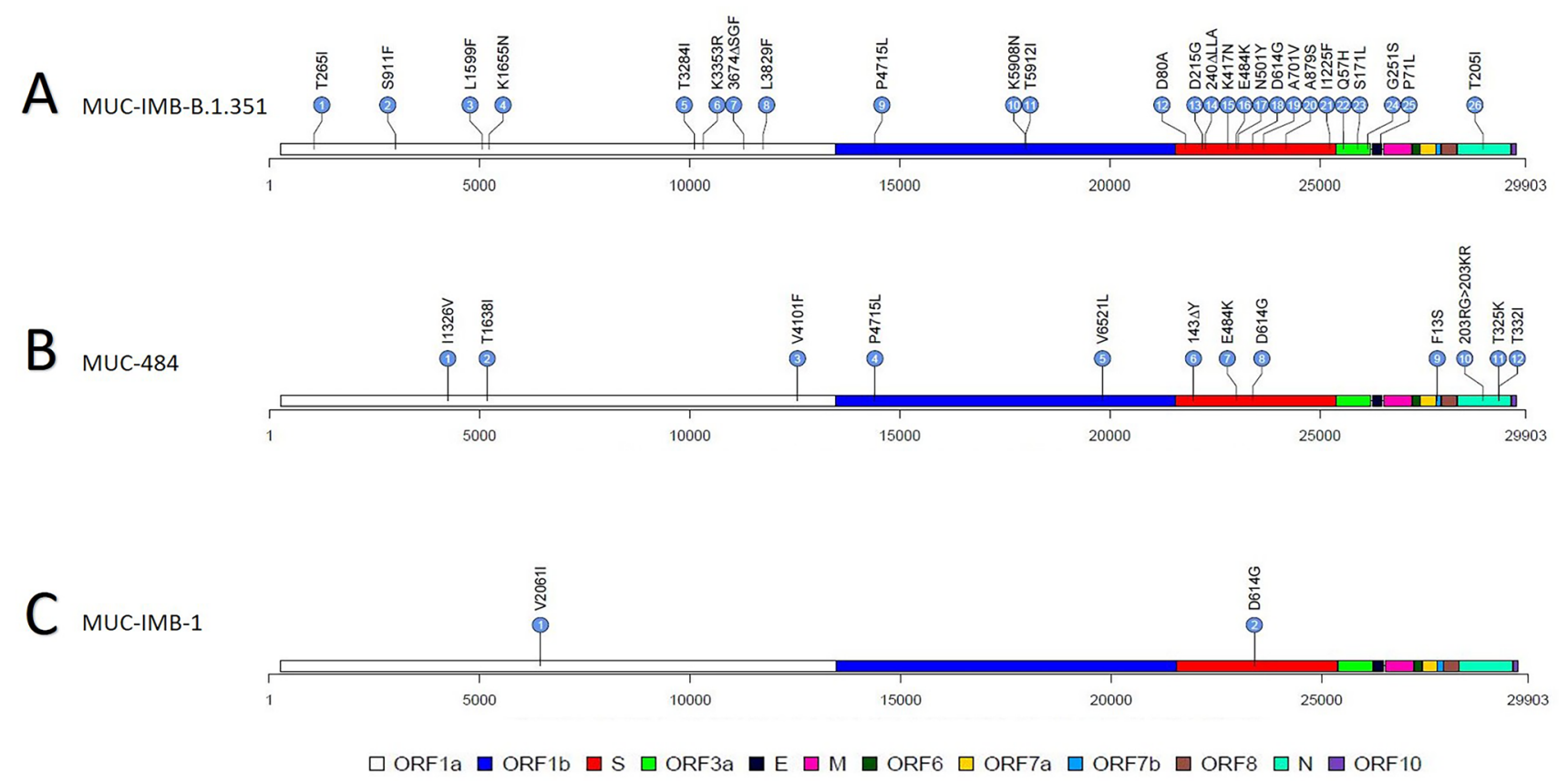

Fig. 1 Lollipop plots of all three SARS-CoV-2 strains examined in this study showing all nonsynonymous mutations in their respective genomes. A MUC-IMB-B.1.351 holds 26 mutations distributed over the genome. B MUC-484 shares only a few mutations with lineage B.1.351. C MUC-IMB-1 was used as WT SARS-CoV-2 reference strain 


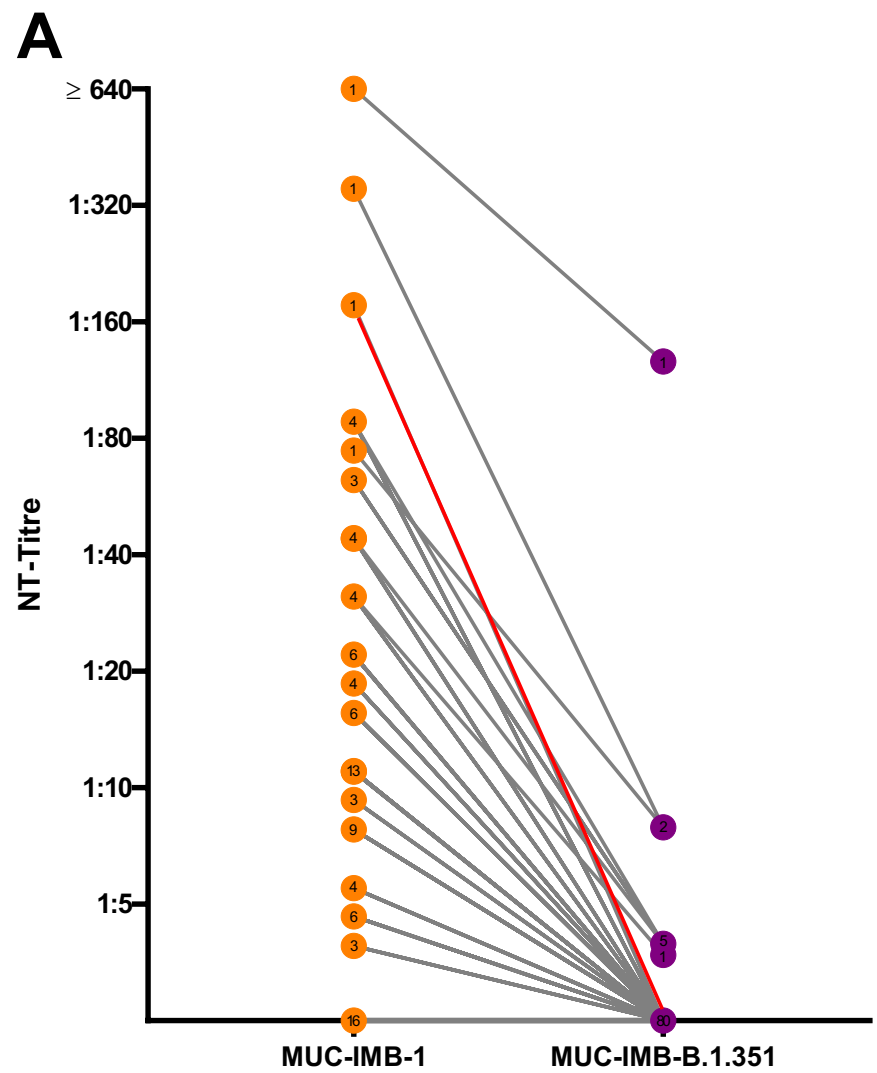

Fig. 2 Comparison of MUC-IMB-1 and MUC-IMB-B.1.351 demonstrates a significant decrease in sensitivity towards NAbs (A) Side by-side comparison of NAbs titres against WT (orange) and MUCIMB-B.1.351 (purple). The greatest decrease was observed in a sample, which dropped from an initial titre of 177 to no neutralising

\section{Sensitivity of MUC-484 to sera from convalescent plasma donors}

Direct comparison of NAbs titres against WT and MUC484 showed that the majority of the tested serum samples ( $\Sigma=80$ ) was unable to retain their neutralising efficacy. Of the 64 samples that were able to neutralise MUC-IMB-1 only one-third (20/64) was also able to neutralise MUC-484. At the same time, a notable reduction in NAbs titres was observed for 18 of these samples with a median decrease of $89.6 \%$. Two samples showed a slight increase in neutralisation when tested against MUC-484. A total of 44 samples showed no neutralisation when tested against MUC-484 although they were able to neutralise WT SARS-CoV-2 in parallel control tests. Altogether, the median loss of neutralising efficacy was $90.6 \%$. All 16 samples that initially tested negative for NAbs against WT virus were also unable to neutralise MUC-484 (Fig. 4A \& B). Overall, the observed drop in NAbs titres against MUC-484 compared to WT virus was statistically significant $(p<0.0001$ by Wilcoxon).
B

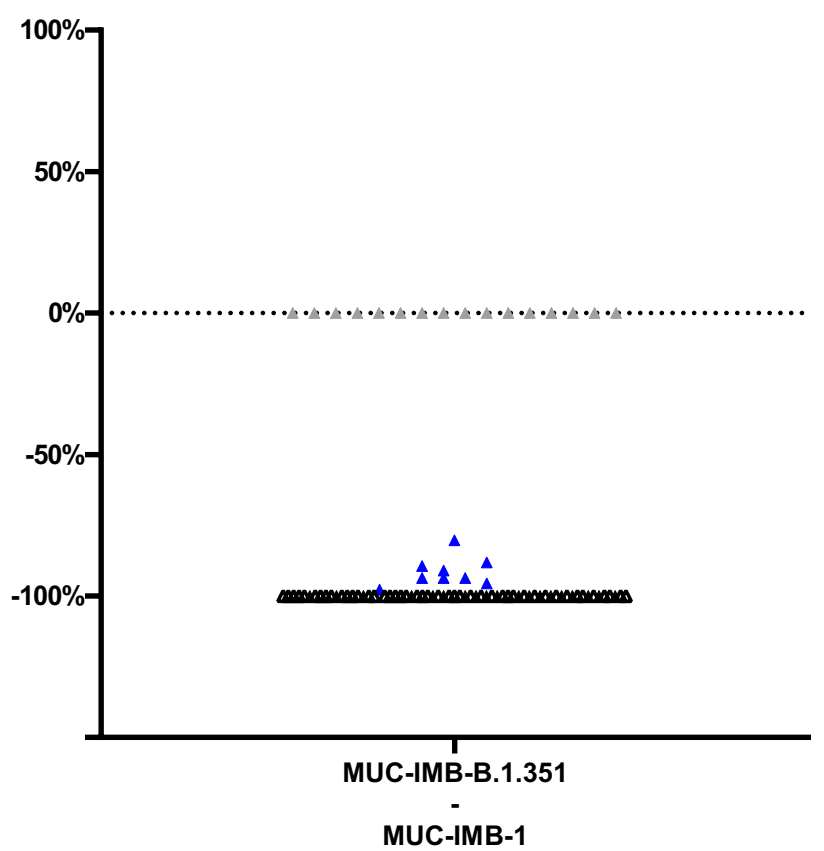

effect against B.1.351 (red). (B) All but nine samples (blue) show a complete loss of neutralising activity (black). All samples that tested negative for NAbs against WT remained negative when tested against MUC-IMB-B.1.351 (grey). ( $\sum$ samples: 89 , the number of overlapping samples is shown in the respective circle)

Pearson regression analysis revealed very limited correlation ( $r=0.37$; 95\% CI: $0.17-0.55)$ between the NAb titre against WT SARS-CoV-2 and the titre against MUC-IMB.1.351 of the same sample (Fig. 5). As the changes in titre were highly variable, no prediction could be made about the neutralising efficacy of a serum against MUC-484 based on the titre against WT SARS-CoV-2.

\section{Discussion}

We investigated the sensitivity of an early circulating SARSCoV-2 and two mutation variants to sera from long-term convalescent plasma donors infected between April and May 2020. Both variants harbour diverse mutations in the gene encoding the $\mathrm{S}$ protein, raising concerns about their humoral immune evasion potential. We used clinical viral isolates instead of pseudoviruses to include the effects of potentially relevant mutations outside the S protein. We isolated MUCIMB-B.1.351 from an acutely infected individual. Whole 


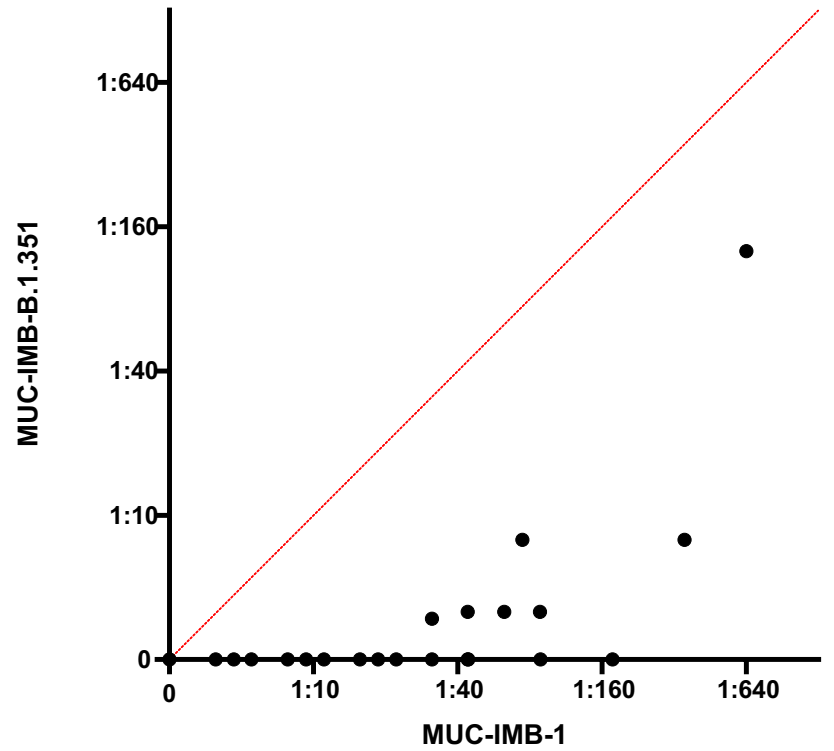

Fig. 3 Correlation plot reveals limited correlation between NAbs titres against MUC-IMB-1 and MUC-IMB-B.1.351 No prediction can be made about the neutralising efficacy of a serum against MUCB.1.351 based on the NAbs titre of the same sample against WT SARS-CoV-2 and vice versa $(r=0.53,95 \%$ CI: $0.37-0.67$ Pearson regression analysis)

genome sequencing assigned the isolate to lineage B.1.351 and revealed ten nonsynonymous mutations in the $\mathrm{S}$ protein relative to the original Wuhan sequence. MUC-484 was isolated from an immunocompromised patient with a prolonged SARS-CoV-2 infection and was first described by Khatamzas et al. [5]. As shown, it holds three nonsynonymous mutations in the S protein. Early isolated MUC-IMB-1 was used as WT reference strain with only two mutations in total, one of which is located in the S protein.

Substitution D614G is the only S mutation that is present in all three strains examined in this study including the WT reference strain. It could therefore not be assessed with regard to its influence on neutralisation sensitivity. However, numerous studies suggest that the D614G mutation increases overall fitness and infectivity but does not seem to promote immune evasion $[19,20]$. Substitutions K417N, E484K, N501Y are commonly associated with VOCs and are of special interest as all of them have been shown to efficiently mediate antibody escape [13, 21]. MUC-484 only acquired the E484K mutation and was highly resistant to convalescent sera in our study with a median loss of neutralising efficacy of $90.6 \%$. For comparison, we found a median decline of $99 \%$ for MUC-IMBB.1.351 carrying all three substitutions. These findings underline that the E484K mutation alone is vigorously reducing neutralisation sensitivity due to its enhancement of hACE2 binding whilst reducing the binding affinities of neutralising monoclonal antibodies [22]. At the same time, this also indicates that even a small number or even a single mutation in the $\mathrm{S}$ protein may be sufficient to significantly reduce antibody-mediated immune protection against SARS-CoV-2. This is also well in line with our recent report on the significant reduction of neutralising activity of the same sera against B.1.1.7. The observed decrease of $47.7 \%$ was less than the reduction we found for the variants tested in this study [4], which is likely because B.1.1.7 misses the vigorous E484K mutation and the observed antibody escape is mediated by N501Y only. Our observation that MUC-IMB-B.1.351 is even more resistant to neutralisation could be explained by the accumulation of additional substitutions (including K417N and $\mathrm{N} 501 \mathrm{Y}$ ). It could also be an indication that $\mathrm{S}$ mutations act synergistically and their effect on each other is enhanced. In addition, the impact of NTD-specific antibodies on virus neutralisation has been described [23]. MUC-IMBB.1.351 carries mutations located within the NTD (i.e. two substitutions and one in-frame deletion) that were previously shown to influence NTD-specific NAbs [24]. Based on our findings, these mutations likely contribute to the neutralisation resistance of MUC-IMB-B.1.351 but appear to play a minor role.

In contrast, we were surprised by the finding that two sera showed increased neutralising activity against MUC-484 (but not MUC-IMB-B.1.351). Interestingly, we observed the same phenomenon with one serum when tested against B.1.1.7 [4]. This could indicate that in rare cases polyvalent antibody formation could also improve neutralisation against variants. However, this could be contradicted by the fact that this effect was observed in different samples in each case. This is consistent with structural predictions showing that K417N and E484K inhibit the binding of different monoclonal antibodies and can therefore act synergistically in a polyclonal serum [22].

The fact that the E484K emerged independently in an immunocompromised patient with prolonged infection under plasma donation treatment [5] and is highly resistant to neutralisation is particularly striking. It highlights the problem that it is not only necessary to monitor the emergence of variants at the population level, but also for individual patients in some circumstances. Especially in severe and longstanding COVID-19 cases, treatment with convalescent plasma seems to promote the emergence of escape variants and decrease the efficacy of plasma therapy over time [25, 26].

The fact that no prediction could be made about the neutralising efficacy of a serum against either variant based on the NAbs titre of the same sample against WT SARSCoV-2 must be considered, especially for the therapeutic use of convalescent plasma. Ideally, the neutralising efficacy of convalescent plasma should be determined against the major virus clades circulating at that time and administered to patients infected with a well-neutralised clade whenever 


\section{A}

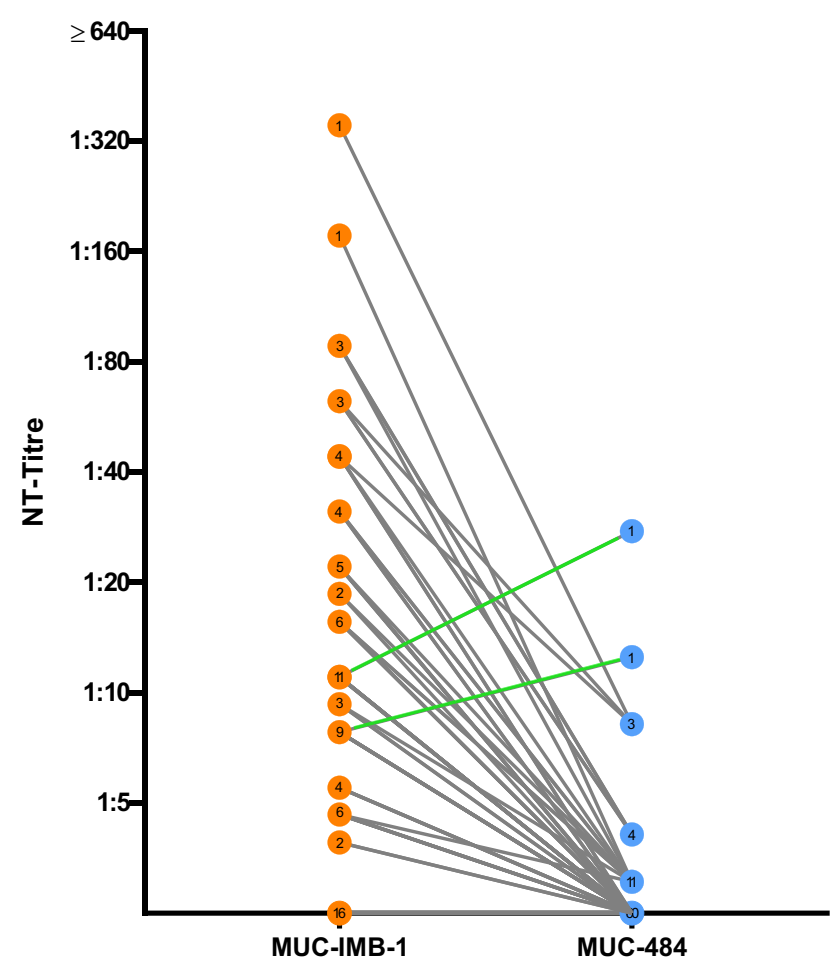

Fig. 4 Comparison of MUC-IMB-1 and MUC-484 demonstrates an overall decrease in sensitivity towards NAbs (A) Side-by-side comparison of WT (orange) and MUC-484 (blue) reveals an overall decrease in NAbs titre levels with the exception of only two samples depicted in green, showing a lowgrade increase in titre level from 11 to 27.6 and 7.8 to 12.5 , respectively. (B) Whilst one third of samples was still able to neutralise MUC-484 (blue), a notable decrease in titre levels can be observed for all but two of those samples with a

possible. This includes that NAbs detection assays such as virus neutralization tests (VNT) or surrogate tests should be continuously adapted to cover current virus clades.

A potential limitation of our study is its relatively low number of tested samples as well the overall low titres of these samples, which might lead to an overestimation of the variants immune escape potential In addition, we could not include in our investigations the potentially pre-existing cellular immune response, which might be more cross-reactive
B

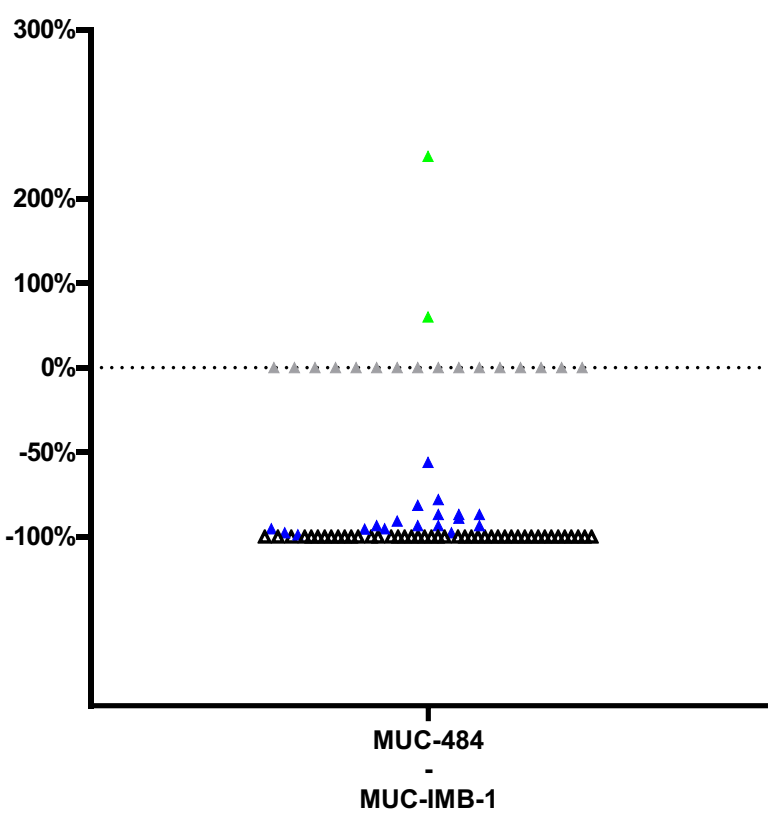

median decrease of $97.1 \%$. Two samples show an increase in neutralising activity (green). The remaining two-thirds of the samples show a complete loss of neutralising efficacy against MUC-IMB-1 (black) whilst all 16 samples that tested negative for NAbs against MUCIMB-1 remained negative when tested against MUC-484 (grey). ( $\sum$ samples: 80 ; the number of overlapping samples is shown in the respective circle)

than NAbs. Thus, future studies focussing on the cellular immune response are needed.

Overall, our study highlights the humoral immune evasion potential not only of globally circulating VOCs such as B.1.351 but also of variants emerging in patients under plasma therapy. Mutations of the $\mathrm{S}$ protein are of particular interest and we demonstrate that different mutations and combinations thereof can be associated with a reduction up to complete loss of neutralising antibody cross-reactivity against novel emerging viral strains. 


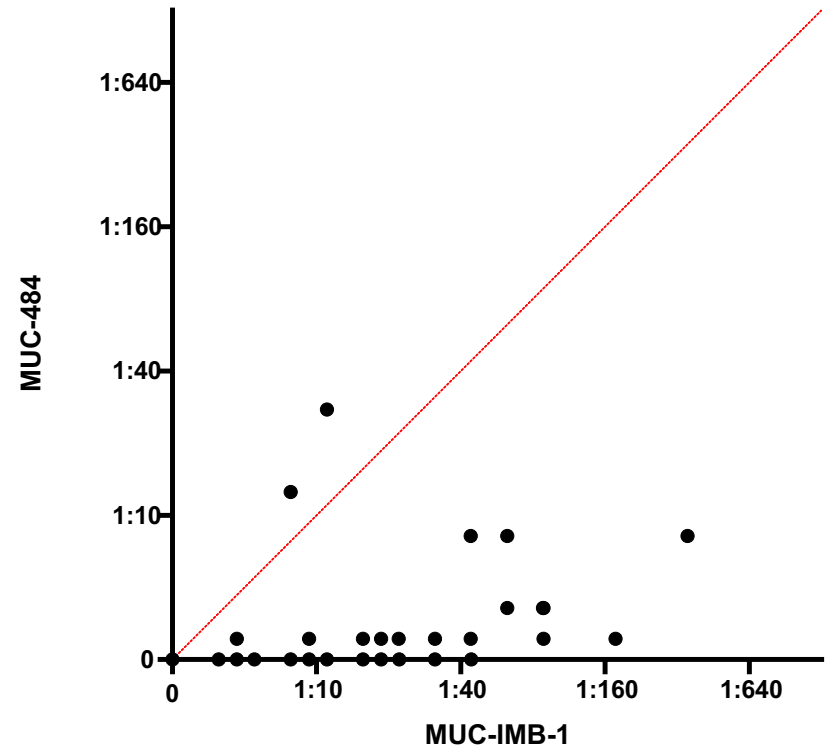

Fig. 5 Correlation plot reveals very limited correlation between NAbs titres against MUC-IMB-1 and MUC-484 Based on the very limited correlation, no predictions can be made about the neutralising effect of a serum against MUC-484 based on the titre of the same sample against WT SARS-CoV-2 $(r=0.37,95 \%$ CI: $0.17-0.55$ Pearson regression analysis)

Funding Open Access funding enabled and organized by Projekt DEAL. This study was funded by the Medical Biodefense Research Program of the Bundeswehr Medical Service.

Data availability The data presented in this study are available on request from the corresponding author. The data are not publicly available due to privacy restrictions.

Code availability Not applicable.

\section{Declarations}

Conflict of interest The authors declare no conflict of interest.

Ethical approval The study was carried out in-line with "The Code of Ethics of the World Medical Association (Declaration of Helsinki)". The use of serum samples complied with the guidelines of the Central Ethics Committee of the German Medical Association (Dtsch Arztebl 2003; 100(23): A-1632). In accordance with these guidelines, the anonymized use of residual material from the samples sent to our laboratory for diagnostic purposes is permissible, provided that the patients have not decided against this procedure. Samples from patients who had decided against this procedure were excluded from the analyses.

Open Access This article is licensed under a Creative Commons Attribution 4.0 International License, which permits use, sharing, adaptation, distribution and reproduction in any medium or format, as long as you give appropriate credit to the original author(s) and the source, provide a link to the Creative Commons licence, and indicate if changes were made. The images or other third party material in this article are included in the article's Creative Commons licence, unless indicated otherwise in a credit line to the material. If material is not included in the article's Creative Commons licence and your intended use is not permitted by statutory regulation or exceeds the permitted use, you will need to obtain permission directly from the copyright holder. To view a copy of this licence, visit http://creativecommons.org/licenses/by/4.0/.

\section{References}

1. Yang Y, Du L (2021) SARS-CoV-2 spike protein: a key target for eliciting persistent neutralizing antibodies. Sig Transduct Target Ther 6:95. https://doi.org/10.1038/s41392-021-00523-5

2. Gaebler C, Wang Z, Lorenzi JCC, Muecksch F, Finkin S, Tokuyama M, Cho A, Jankovic M, Schaefer-Babajew D, Oliveira TY, Cipolla M, Viant C, Barnes CO, Bram Y, Breton G, Hägglöf T, Mendoza P, Hurley A, Turroja M, Gordon K, Millard KG, Ramos V, Schmidt F, Weisblum Y, Jha D, Tankelevich M, Martinez-Delgado G, Yee J, Patel R, Dizon J, Unson-O’Brien C, Shimeliovich I, Robbiani DF, Zhao Z, Gazumyan A, Schwartz RE, Hatziioannou T, Bjorkman PJ, Mehandru S, Bieniasz PD, Caskey M, Nussenzweig MC (2021) Evolution of antibody immunity to SARS-CoV-2. Nature 591:639-644. https://doi.org/10.1038/ s41586-021-03207-w

3. Harvey WT, Carabelli AM, Jackson B, Gupta RK, Thomson EC, Harrison EM, Ludden C, Reeve R, Rambaut A, COVID-19 Genomics UK (COG-UK) Consortium, Peacock SJ, Robertson DL (2021) SARS-CoV-2 variants, spike mutations and immune escape. Nat Rev Microbiol 19:409-424. https://doi.org/10.1038/ s41579-021-00573-0

4. Müller K, Girl P, Giebl A, von Buttlar H, Dobler G, Bugert JJ, Gruetzner S, Wölfel R (2021) Emerging SARS-CoV-2 variant B.1.1.7 reduces neutralisation activity of antibodies against wildtype SARS-CoV-2. J Clin Virol 142:104912. https://doi.org/10. 1016/j.jcv.2021.104912

5. Khatamzas E, Rehn A, Muenchhoff M, Hellmuth J, Gaitzsch E, Weiglein T, Georgi E, Scherer C, Stecher S, Weigert O, Girl P, Zange S, Keppler OT, Stemmler J, Bergwelt-Baildon M von, Wölfel R, Antwerpen M (2021) Emergence of multiple SARSCoV-2 mutations in an immunocompromised host. medRxiv 2021.01.10.20248871. https://doi.org/10.1101/2021.01.10. 20248871

6. Wölfel R, Corman VM, Guggemos W, Seilmaier M, Zange S, Müller MA, Niemeyer D, Jones TC, Vollmar P, Rothe C, Hoelscher M, Bleicker T, Brünink S, Schneider J, Ehmann R, Zwirglmaier K, Drosten C, Wendtner C (2020) Virological assessment of hospitalized patients with COVID-2019. Nature 581:465-469. https://doi.org/10.1038/s41586-020-2196-x

7. World Health Organization (WHO) (2021) Tracking SARSCoV-2 variants. https://www.who.int/activities/tracking-SARSCoV-2-variants. Accessed 26 Jul 2021

8. Tegally H, Wilkinson E, Giovanetti M, Iranzadeh A, Fonseca V, Giandhari J, Doolabh D, Pillay S, San EJ, Msomi N, Mlisana K, von Gottberg A, Walaza S, Allam M, Ismail A, Mohale T, Glass AJ, Engelbrecht S, Van Zyl G, Preiser W, Petruccione F, Sigal A, Hardie D, Marais G, Hsiao N, Korsman S, Davies M-A, Tyers L, Mudau I, York D, Maslo C, Goedhals D, Abrahams S, Laguda-Akingba O, Alisoltani-Dehkordi A, Godzik A, Wibmer CK, Sewell BT, Lourenço J, Alcantara LCJ, Kosakovsky Pond SL, Weaver S, Martin D, Lessells RJ, Bhiman JN, Williamson C, de Oliveira T (2021) Detection of a SARS-CoV-2 variant of concern in South Africa. Nature 592:438-443. https://doi.org/ $10.1038 / \mathrm{s} 41586-021-03402-9$ 
9. Jangra S, Ye C, Rathnasinghe R, Stadlbauer D, Alshammary H, Amoako AA, Awawda MH, Beach KF, Bermúdez-González MC, Chernet RL, Eaker LQ, Ferreri ED, Floda DL, Gleason CR, Kleiner G, Jurczyszak D, Matthews JC, Mendez WA, Mulder LCF, Russo KT, Salimbangon A-BT, Saksena M, Shin AS, Sominsky LA, Srivastava K, Krammer F, Simon V, Martinez-Sobrido L, García-Sastre A, Schotsaert M (2021) SARSCoV-2 spike E484K mutation reduces antibody neutralisation. The Lancet Microbe 2:e283-e284. https://doi.org/10.1016/ S2666-5247(21)00068-9

10. Zhou D, Dejnirattisai W, Supasa P, Liu C, Mentzer AJ, Ginn HM, Zhao Y, Duyvesteyn HME, Tuekprakhon A, Nutalai R, Wang B, Paesen GC, Lopez-Camacho C, Slon-Campos J, Hallis B, Coombes N, Bewley K, Charlton S, Walter TS, Skelly D, Lumley SF, Dold C, Levin R, Dong T, Pollard AJ, Knight JC, Crook D, Lambe T, Clutterbuck E, Bibi S, Flaxman A, Bittaye M, Belij-Rammerstorfer S, Gilbert S, James W, Carroll MW, Klenerman P, Barnes E, Dunachie SJ, Fry EE, Mongkolsapaya J, Ren J, Stuart DI, Screaton GR (2021) Evidence of escape of SARS-CoV-2 variant B.1.351 from natural and vaccine-induced sera. Cell 184:2348-2361.e6. https://doi.org/10.1016/j.cell. 2021.02.037

11. Davies NG, Abbott S, Barnard RC, Jarvis CI, Kucharski AJ, Munday J, Pearson CAB, Russell TW, Tully DC, Washburne AD, Wenseleers T, Gimma A, Waites W, Wong KL, Zandvoort K van, Silverman JD, Group CC-19 W, Diaz-Ordaz K, Keogh R, Eggo RM, Funk S, Jit M, Atkins KE, Edmunds WJ (2021) Estimated transmissibility and severity of novel SARS-CoV-2 variant of concern 202012/01 in England. medRxiv 2020.12.24.20248822. https://doi.org/10.1101/2020.12.24.20248822

12. US Food and Drug Administration (2021) Fact sheet for health care providers emergency use authorization (EUA) of Bamlanivimab

13. Planas D, Bruel T, Grzelak L, Guivel-Benhassine F, Staropoli I, Porrot F, Planchais C, Buchrieser J, Rajah MM, Bishop E, Albert M, Donati F, Prot M, Behillil S, Enouf V, Maquart M, SmatiLafarge M, Varon E, Schortgen F, Yahyaoui L, Gonzalez M, De Sèze J, Péré H, Veyer D, Sève A, Simon-Lorière E, Fafi-Kremer S, Stefic K, Mouquet H, Hocqueloux L, van der Werf S, Prazuck T, Schwartz O (2021) Sensitivity of infectious SARS-CoV-2 B.1.1.7 and B.1.351 variants to neutralizing antibodies. Nat Med 27:917-924. https://doi.org/10.1038/s41591-021-01318-5

14. Korber B, Fischer WM, Gnanakaran S, Yoon H, Theiler J, Abfalterer W, Hengartner N, Giorgi EE, Bhattacharya T, Foley B, Hastie KM, Parker MD, Partridge DG, Evans CM, Freeman TM, de Silva TI, Angyal A, Brown RL, Carrilero L, Green LR, Groves DC, Johnson KJ, Keeley AJ, Lindsey BB, Parsons PJ, Raza M, Rowland-Jones S, Smith N, Tucker RM, Wang D, Wyles MD, McDanal C, Perez LG, Tang H, Moon-Walker A, Whelan SP, LaBranche CC, Saphire EO, Montefiori DC (2020) Tracking changes in SARS-CoV-2 spike: evidence that D614G increases infectivity of the COVID-19 virus. Cell 182:812-827.e19. https:// doi.org/10.1016/j.cell.2020.06.043

15. Paul-Ehrlich-Institut-News-Recommendation of the PaulEhrlich-Institut for the collection and manufacture of COVID19 convalescent plasma. https://www.pei.de/EN/newsroom/hpnews/2020/200407-recommendation-pei-covid-19-convalesce nt-plasma.html;jsessionid=75FE2CC97FB1AC74E8529A023 B965614.intranet241. Accessed 15 Mar 2021

16. (2021) CD8 T cells and antibodies drive SARS-CoV-2 evolution in chronic infection. https://www.researchsquare.com. Accessed 17 Sep 2021
17. Ou J, Zhu LJ (2019) trackViewer: a bioconductor package for interactive and integrative visualization of multi-omics data. Nature Methods. https://www.nature.com/articles/s41592-0190430-y?proof=t. Accessed 17 Sep 2021

18. Haselmann V, Özçürümez MK, Klawonn F, Ast V, Gerhards C, Eichner R, Costina V, Dobler G, Geilenkeuser W-J, Wölfel $R$, Neumaier M (2020) Results of the first pilot external quality assessment (EQA) scheme for anti-SARS-CoV2-antibody testing. Clin Chem Lab Med. https://doi.org/10.1515/cclm-2020-1183

19. Huang S-Y, Kung Y-A, Huang P-N, Chang S-Y, Gong Y-N, Han Y-J, Chiang H-J, Liu K-T, Lee K-M, Chang C-Y, Chang C-C, Huang C-G, Shih S-R (2021) Stability of SARS-CoV-2 spike G614 variant surpasses that of the D614 variant after cold storage. mSphere 6:e00104-21. https://doi.org/10.1128/mSphere.00104-21

20. Ozono S, Zhang Y, Ode H, Sano K, Tan TS, Imai K, Miyoshi K, Kishigami S, Ueno T, Iwatani Y, Suzuki T, Tokunaga K (2021) SARS-CoV-2 D614G spike mutation increases entry efficiency with enhanced ACE2-binding affinity. Nat Commun 12:848. https://doi.org/10.1038/s41467-021-21118-2

21. Li Q, Nie J, Wu J, Zhang L, Ding R, Wang H, Zhang Y, Li T, Liu S, Zhang M, Zhao C, Liu H, Nie L, Qin H, Wang M, Lu Q, Li X, Liu J, Liang H, Shi Y, Shen Y, Xie L, Zhang L, Qu X, Xu W, Huang W, Wang Y (2021) SARS-CoV-2 501Y.V2 variants lack higher infectivity but do have immune escape. Cell 184:23622371.e9. https://doi.org/10.1016/j.cell.2021.02.042

22. Gan HH, Twaddle A, Marchand B, Gunsalus KC (2021) Structural modeling of the SARS-CoV-2 spike/human ACE2 complex interface can identify high-affinity variants associated with increased transmissibility. J Mol Biol 433:167051. https://doi.org/10.1016/j. jmb.2021.167051

23. Liu L, Wang P, Nair MS, Yu J, Rapp M, Wang Q, Luo Y, Chan JF-W, Sahi V, Figueroa A, Guo XV, Cerutti G, Bimela J, Gorman J, Zhou T, Chen Z, Yuen K-Y, Kwong PD, Sodroski JG, Yin MT, Sheng Z, Huang Y, Shapiro L, Ho DD (2020) Potent neutralizing antibodies against multiple epitopes on SARS-CoV-2 spike. Nature 584:450-456. https://doi.org/10.1038/s41586-020-2571-7

24. McCallum M, De Marco A, Lempp FA, Tortorici MA, Pinto D, Walls AC, Beltramello M, Chen A, Liu Z, Zatta F, Zepeda S, di Iulio J, Bowen JE, Montiel-Ruiz M, Zhou J, Rosen LE, Bianchi S, Guarino B, Fregni CS, Abdelnabi R, Foo S-YC, Rothlauf PW, Bloyet L-M, Benigni F, Cameroni E, Neyts J, Riva A, Snell G, Telenti A, Whelan SPJ, Virgin HW, Corti D, Pizzuto MS, Veesler D (2021) N-terminal domain antigenic mapping reveals a site of vulnerability for SARS-CoV-2. Cell 184:2332-2347.e16. https:// doi.org/10.1016/j.cell.2021.03.028

25. Colson P, Devaux CA, Lagier J-C, Gautret P, Raoult D (2021) A possible role of remdesivir and plasma therapy in the selective sweep and emergence of new SARS-CoV-2 variants. J Clin Med 10:3276. https://doi.org/10.3390/jcm10153276

26. Weisblum Y, Schmidt F, Zhang F, DaSilva J, Poston D, Lorenzi JC, Muecksch F, Rutkowska M, Hoffmann H-H, Michailidis E, Gaebler C, Agudelo M, Cho A, Wang Z, Gazumyan A, Cipolla M, Luchsinger L, Hillyer CD, Caskey M, Robbiani DF, Rice CM, Nussenzweig MC, Hatziioannou T, Bieniasz PD (2020) Escape from neutralizing antibodies by SARS-CoV-2 spike protein variants. eLife 9:e61312. https://doi.org/10.7554/eLife.61312

Publisher's Note Springer Nature remains neutral with regard to jurisdictional claims in published maps and institutional affiliations. 